\title{
The Operation and Control Strategy of Energy Storage System in the
}

\section{Micro-Grid}

\author{
Yuan Liu, ${ }^{1, a}$, Jianlin $\mathrm{Li}^{\mathrm{i}, \mathrm{b}}$ and Tiejiang Yuan ${ }^{3, \mathrm{c}}$ \\ ${ }^{1}$ College of Electrical Engineering, Xinjiang University, Urumqi 830002, China; \\ ${ }^{2}$ China Electric Power Research Institute, Beijing 100192, China \\ ${ }^{3}$ College of Electrical Engineering, Xinjiang University, Urumqi 830002, China; \\ a827273384@qq.com, bdkylj1@163.com, xjuytj@163.com
}

\section{Key words: Energy Storage; Micro-grid; PQ Control; VF Control}

Abstract: The photovoltaic (PV) power surges with varied with sunlight intensity and temperature, resulting in great fluctuation of power on the side of synchronization on AC busbar micro-grid. Configuring an energy storage system may allow that the grid output is fallen into a specified interval for the purpose of reduction in grid transmission capacity. The energy conversion device of the energy storage system is designed with two stages. The inverter control strategy includes PQ control mode, VF control mode and constant-voltage charging/discharging mode on the battery side. The chopper control strategy uses control DC busbar voltage stability mode. The reliability of control strategies is verified by simulation, which are able to quickly follow up instruction change and suppress disturbance.

\section{Introduction}

The solar energy is a kind of renewable energy resource and has a huge potential. It is reported that the electric energy converted from $5 \%$ of $0.1 \%$ solar radiation received by earth's surface can accommodate the consumption for 40 years in the world. However, a PV plant has very bad output power stability due to cyclic sunlight and constantly fluctuated temperature, usually causing voltage fluctuation even power interruption. The development and application of the stored-energy technology may solve the problems of randomness and fluctuation of PV power generation, realize the smooth output of it, and regulate the variation in grid voltage, frequency and phase caused by power surge.

The common energy storage includes pumped energy storage, compressed air energy storage, battery energy storage, flywheel energy storage and super capacitor, superconductor energy storage, etc. At present, the battery energy storage system is widely used in a PV micro-grid, which consists of battery and power conversion system (PCS). In China, the batteries commonly used in a micro-grid include lithium ion battery, sodium-sulfur battery, vanadium flow battery, etc. In the article, lithium ion batteries are used. They features various advantages such as high energy storage density, high efficiency of energy storage, small self-discharging capacity, strong adaptability, long cycle life, etc.

As demanded, PCS must be designed with PQ and VF operational modes[1]. In PQ mode, it may control active power and reactive power output as per scheduling order, and, is able to operate in four quadrants at full capacity. In VF mode, the battery keeps the AC busbar voltage constant. According to the characteristics of lithium ion battery, it is necessary that PCS features constant voltage control on the battery side[2,3]. In this article, the chopper is proposed to be responsible for step-up voltage and for realizing constant DC busbar voltage[4,5]. And, the inverter is used to 
realize PQ control, VF control and constant voltage control on the battery side. In the article, LCL filters are used. Compared to conventional L and LC filters, an LCL filter may better suppress high order harmonic component, effectively reduce the inductance value and improve the dynamic performance of the system. And, it is less affected by grid.

\section{Topological Structure and Operational Modes of System}

Fig.1 shows the topological structure of PV energy storage micro-grid system. With classic secondary conversion, the PV components may output maximum power of PV voltage and controls the stable DC bus voltage so that the AC voltage phase is synchronized with grid.

With circuit breakers QF4 and QF1, the grid is connected to PV micro-grid system. The common loads are connected to grid via circuit breakers QF5 and QF4 and to AC busbar via circuit breakers QF5 and QF1.

With half-bridge chopper, the energy storage unit steps up the voltage to a fixed value, and then connected to the AC busbar via converter and circuit breaker QF2. The converter is responsible for power control of energy storage system. The important loads are connected to the AC busbar via the circuit breaker QF3.

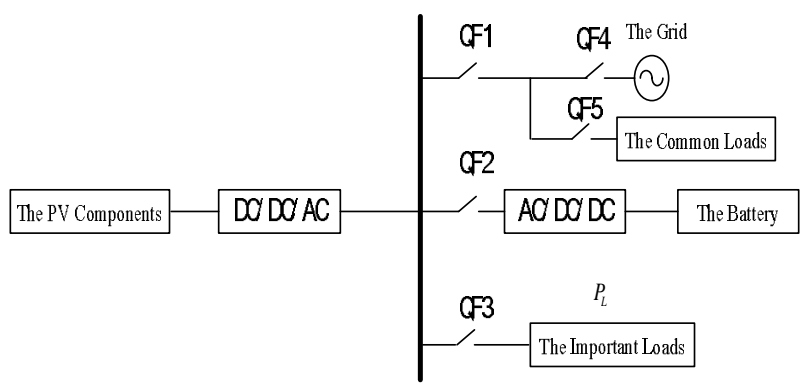

Fig.1 Topological Structure of PV Energy Storage Micro-grid System

Usually, for micro-grid system with AC busbar, there are three operational modes including synchronized integral operation, synchronized energy-storage by-pass operation and PV energy-storage independent operation. They are analyzed as follows.

Mode 1: QF1, QF2, QF3 closed. Both PV system and energy storage system are put into service. In case of sufficient sunlight intensity, for PV power generation, not only the demands of important loads will be met, but also the excessive energy will be transferred to the energy storage system and grid. The power of energy storage system should be controlled. If the energy needed for PV micro-grid system is greater than the upper limit setpoint of grid fed power, the energy storage system absorbs energy to meet the demands so that the transmission power to grid is lower than the upper limit setpoint of grid fed power. If case of insufficient sunlight intensity, now it is possible that the load is higher than PV generated energy. As a result, it is necessary to introduce electricity from the grid. If the grid generated energy is higher than the upper limit setpoint of grid generated power, the energy storage system releases energy so that the grid generated energy is not out of the limit.

Mode 2: QF1 and QF3 closed and QF2 opened Compared to Mode 1, the energy storage system is not in service. In general, this mode occurs in the following circumstances: 1) The energy-storage power transmission capacity should be zero if the grid transmission power to PV energy storage system micro-grid system meets the specified requirements of grid transmission interval, Now, introduction to this mode may reduce the loss in inverter and chopper, resulting in increased operating efficiency of system. 2) If it is necessary to regularly calibrate and replace the battery set, 
switching into this mode may be made when grid transmission meets the specified requirements of grid transmission interval or when the grid absorbed power exceeds the limit. (Now, the PV generated energy may be reduced.) 3) In case of failure to energy-storage system or if the energy storage system SOC is less than the lower limit and it is necessary that the energy storage system generates, all the common loads will be cut out, with QF5 opened, to ensure supply to important load.

Mode 3: With QF2 and QF3 closed and QF1 opened, both energy storage system and UPS system are putting into operation. Mostly, this mode occurs at condition that there is no sunlight at night and the energy storage SOC is higher. The loads are maintained relying on the remaining quantity of electricity of the energy storage system. This reduces the probability of PV abandonment behavior occurrence, fully utilizing energy generated from renewable energy resources, and improving economic performance of operating system.

\section{Control Strategy of Energy Storage System}

Control Rules of Energy Storage System. The main circuit of the energy storage system is as shown in Fig.2. And, the PCS consists of inverter and many choppers. It is required that the PCS should be operated in both PQ and V/F modes because the operating modes of micro-grid include synchronizing and islanding modes. And for the purpose of self protection, the energy storage system must be designed with constant-voltage charging/discharging function.

The AC busbar voltage is stabilized under about $400 \mathrm{~V}$. The voltage on the inverter DC side of circuit, generated by SPWM pulse, is higher than the peak phase voltage outside filter. Therefore, it is necessary to step the DC side voltage up to V. It is assumed that the battery voltage is step up by $800 \mathrm{~V}$.

In this article, the chopper is responsible for step-up voltage and for realizing constant DC busbar voltage. And, the inverter is used to realize PQ control, VF control and constant voltage control on the battery side.

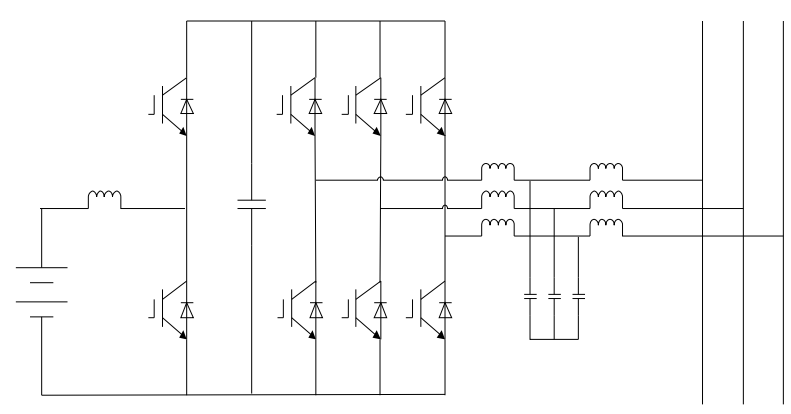

Fig.2 Main Circuit of Energy Storage System

Control Strategy of Chopper. The DC/DC converter is mainly to step the energy storage voltage up to the fixed value. In the article, a half-bridge chopper is used, which may be operated in step-up mode or step-down mode. The control strategy is the PI control of outer voltage loop and inner current loop.

Eq.1 is the inner current loop control equation in step-up mode, inner current loop control equation in step-down mode, and outer voltage loop control. 


$$
\left\{\begin{array}{c}
D=\frac{\left(K_{p 1}+K_{i 1} / s\right)\left(I_{b a t_{-} r e f}-I_{b a t}\right)+U_{d c}-U_{b a t}}{U_{d c}} \\
D=\frac{-\left(K_{p 1}+K_{i 1} / s\right)\left(I_{b a t_{-} r e f}-I_{b a t}\right)+U_{b a t}}{U_{d c}} \\
\left(K_{p 2}+K_{i 2} / s\right)\left(U_{d c_{-} r e f}-U_{d c}\right)=I_{b a t_{-} \text {ref }}
\end{array}\right.
$$

PQ Control of the Inverter. In synchronizing mode, the inverter operates in PQ control mode. It consists of outer power loop and inner current loop. The outer power loop is as shown in Fig.3.

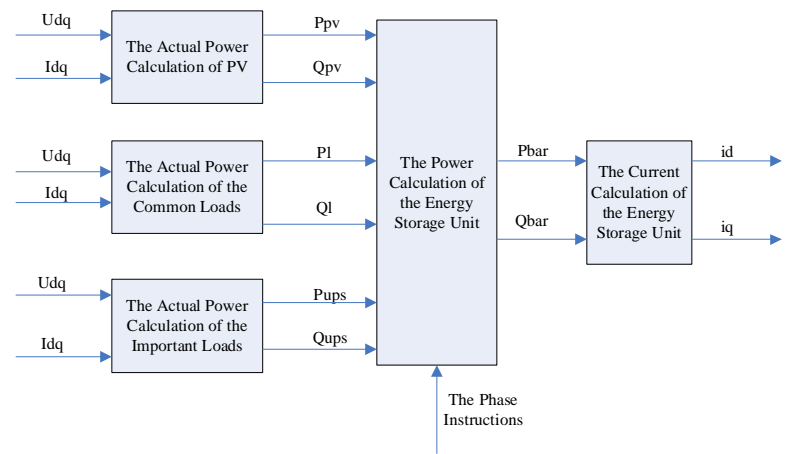

Fig.3 Operational Circuit of Order Current

The current order values idref and iqref on axes $d$ and q may be obtained by the calculated Pref and given Qref according to Eq.2. And, quick tracking is made to grid-side current with inner current loop, as shown in Eq.3. The AC-side reference voltage is vd. The vq is inverted to obtain the 3-phase voltage reference values via dq-abc, which are compared to triangular carrier during generation of SPWM modulated wave.

$$
\begin{aligned}
& \left\{\begin{array}{l}
i_{d_{-} \text {ref }}=\frac{2}{3}\left(\frac{P_{r e f} u_{d}+Q_{r e f} u_{q}}{u_{d}^{2}+u_{q}^{2}}\right) \\
i_{q_{-} \text {ref }}=\frac{2}{3}\left(\frac{P_{r e f} u_{q}-Q_{r e f} u_{d}}{u_{d}^{2}+u_{q}^{2}}\right)
\end{array}\right. \\
& \left\{\begin{array}{l}
v_{d}=-\left(K_{p}+\frac{K_{l}}{S}\right)\left(i_{d_{-} r e f}-i_{d}\right)+\omega L i_{q}+e_{d} \\
v_{q}=-\left(K_{p}+\frac{K_{l}}{s}\right)\left(i_{q_{-} r e f}-i_{q}\right)-\omega L i_{d}+e_{q}
\end{array}\right.
\end{aligned}
$$

VF Control of the Inverter. In islanding mode, the system is not supported by grid voltage and frequency. The inverter needs to be switched to the constant voltage and constant frequency (VF) control mode. The VF control differs from PQ control with respect to different attainment method of idref and iqref. the outer voltage loop is obtained by derivation of branch equation at grid-side filtering capacitor node, as shown in Eq.4.

$$
\left\{\begin{array}{l}
i_{d r e f}=C\left(K_{p}+K_{i} / s\right)\left(u_{d r e f}-u_{d}\right)-\omega C u_{q}+i_{g d} \\
i_{q r e f}=C\left(K_{p}+K_{i} / s\right)\left(u_{\text {qref }}-u_{q}\right)-\omega C u_{d}+i_{g q}
\end{array}\right.
$$

In order to ensure smooth switching process, the phase angle in the transition process when switching is determined according to Eq.5. Where, $\theta_{\text {new }}$ is the new angle to be newly transited to; 
$\theta$ is the present angle; $\omega_{\text {ref }}$ is the fixed angular velocity of $100 \mathrm{pi}$; $\mathrm{K}$ is the regulation coefficient.

$$
\theta_{\text {ref }}=\frac{1}{s}\left[K\left(\theta_{\text {new }}-\theta\right)+\omega_{\text {ref }}\right]
$$

Voltage of Inverter Control Battery. For the voltage of inverter control battery, the battery voltage controls the active power of inverter, as shown in Eq.6.

$$
P_{r e f}=\left(K_{p}+\frac{K_{l}}{s}\right)\left(U_{b a t_{-} r e f}-U_{b a t}\right)
$$

\section{Simulation and Analysis}

The simulation block diagram of the whole system is as shown in Fig.4. In PQ mode, the circuit breaker QF4 on the grid side is closed. Externally, the energy storage system is equivalent to a current source, controlling the power on the synchronization side, ensuring that it is not exceeding the limit and reducing the demands of power transmission capacity of power line. In VF mode, the circuit breaker QF4 is opened. Externally, the energy storage system is equivalent to a voltage source.

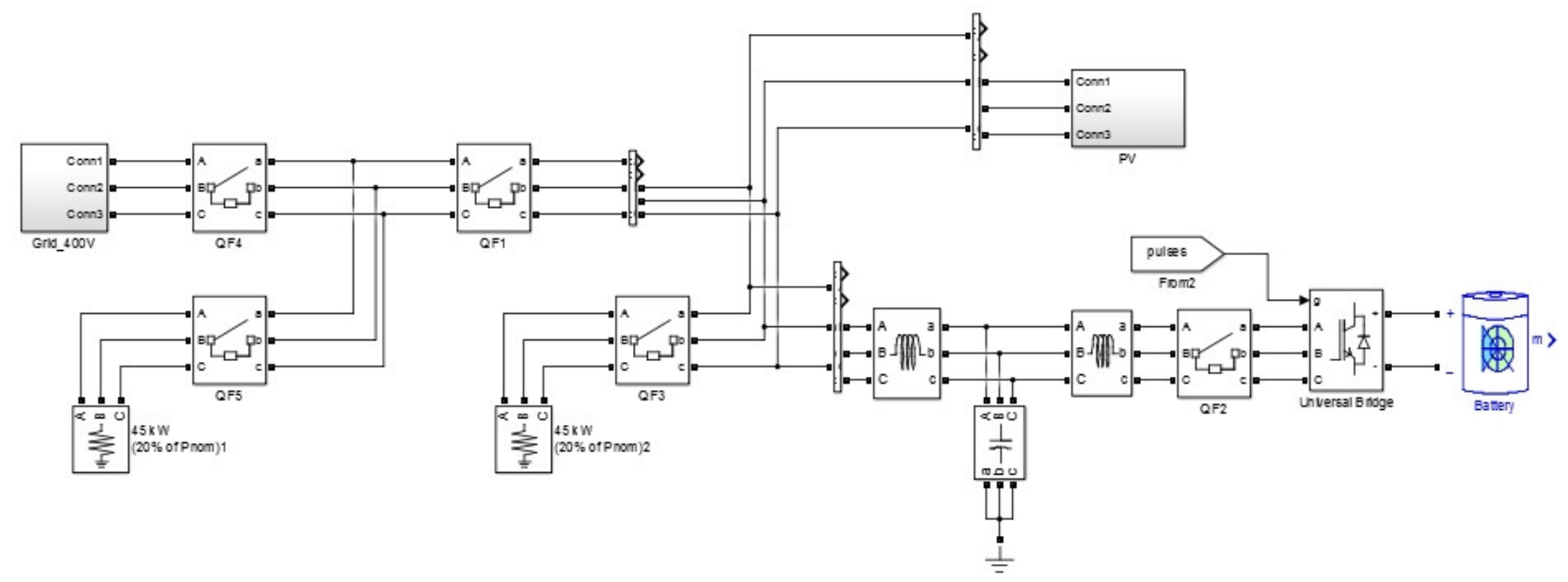

Fig.4 Main Circuit Diagram of System

The system is simulated in hours. In PQ control mode of one-day energy storage, the active powers of PV, load and synchronization side are as shown in Fig.5. Where, the PV output curve is shown by solid line and curve of load by dotted line. The power of energy storage system and grid generated power are obtained by the difference between them and shown with dot-and-dash line. Fig. 5 -a shows that the peak value of load demand is $60 \mathrm{~kW}$. In case of no energy storage system but of PV system only, the peak of grid transmission capacity to system is $30 \mathrm{~kW}$, that is to say, the grid capacity demand can only be reduced by $30 \%$ installed capacity nearly. Fig.5-b shows that, under condition without change in peak value of load demands, if a PV energy storage system is set up, the peak value of grid transmission capacity to system is reduced to $20 \mathrm{~kW}$ and by $40 \%$ grid demands of installed capacity. This means that, without increase in the PV installed capacity, the addition of energy storage system may increase the reduced efficacy of grid demand by $33 \%$. 


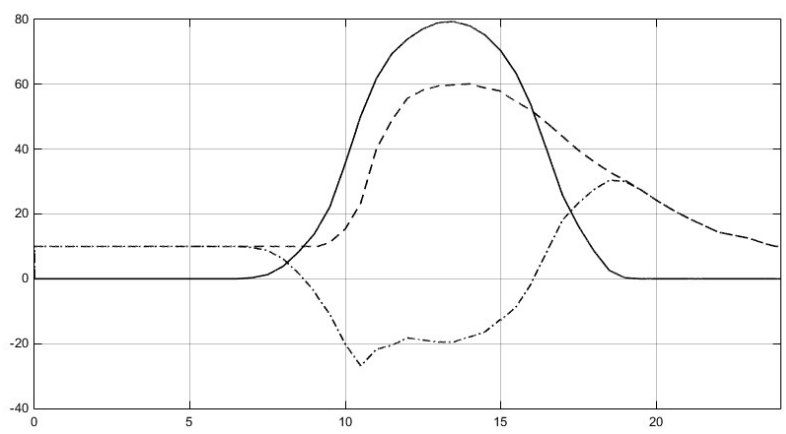

5-a Single PV system

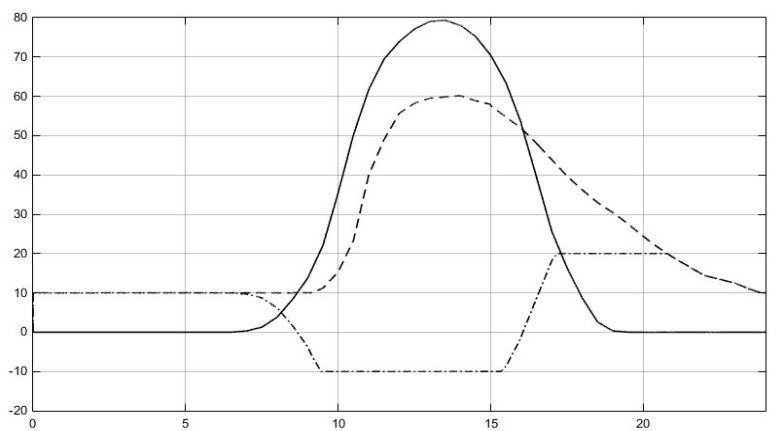

5-b Hybrid PV system with energy storage

Fig.5 Active Powers of PV, Load and Grid Side

By taking two seconds at 13 o'clock in Fig.5-b to be amplified, the waveforms are obtained as shown in Fig.6, from top to bottom indicating the active powers of PV, load and synchronization side. During switching from PQ mode over VF mode, the active power and reactive power on energy storage AC side are as shown in Fig.7. Where, the solid line shows the active power and the dotted lines indicates the reactive power.

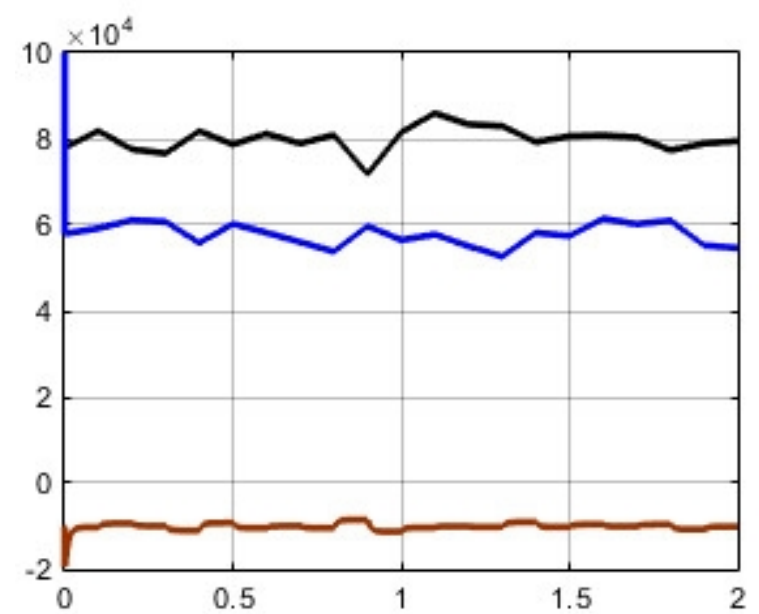

Fig.6 Active Powers of PV, Load and Grid Side

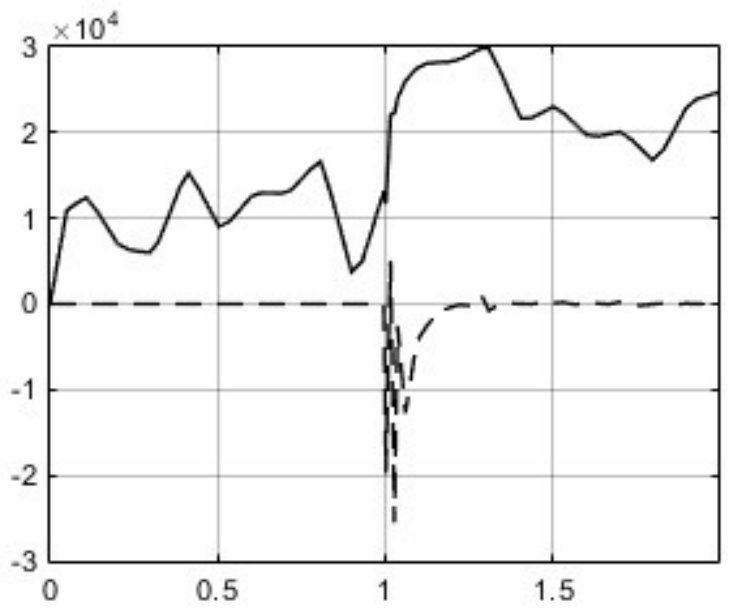

Fig.7 Active Power and Reactive Power on Energy Storage AC Side

\section{Conclusions}

With constantly increased electricity consumption and increasingly large scale of PV in the world, the PV fluctuation has greater and greater influence on grid, causing huge potential trouble to operating safety of electric power system. The study of this article shows that reasonable configuration of energy storage system may not only fulfill the good effect of power smoothing and improve operating efficiency of system, but also improve the economic performance of system and reduce the micro-grid requirements for the capacity of electric power system. The reliability of control strategies is verified by simulation, which are able to quickly follow up instruction change and suppress disturbance.

\section{References}

[1]LI Guan-jun, TAO Yi-bin, HU Jin-hang, SU Guang-ning. Research on Control Strategy of Energy Storage System in Microgrid[J]. Power Electronics, 2013,11:9-11(in Chinese). 
[2]HOU Chaoyong, HU Xuehao, HUI Dong. Design and Implementation of Grid-Connected Converter for Lithium Battery Energy Storage System[J]. Power System Technology, 2012,03:246-251(in Chinese).

[3]HOU Chaoyong, HU Xuehao, HUI Dong. Design and Implementation of Grid-Connected Lithium Battery Energy Storage System under Total Digital Control[J]. Electric Power Automation Equipment, 2012,03:125-130(in Chinese).

[4]LI Jian-lin. Study on Control Methods of Battery Energy Storage Technology[J]. Power System and Clean Energy, 2012,12:61-65(in Chinese).

[5]GAO Zhiqiang, MENG Liang, LIANG Bin, TANG Baofeng, FAN Hui, SUN Zhongji. Control strategies for a photovoltaic-Energy storage hybrid system[J]. Energy Storage Science and Technology, 2013,03:300-306(in Chinese). 